\title{
Rhinacanthus nasutus Ameliorates Cytosolic and Mitochondrial Enzyme Levels in Streptozotocin-Induced Diabetic Rats
}

\author{
Pasupuleti Visweswara Rao, ${ }^{1,2}$ K. Madhavi, ${ }^{3}$ M. Dhananjaya Naidu, ${ }^{4}$ and Siew Hua Gan ${ }^{2}$ \\ ${ }^{1}$ Department of Biotechnology, Sri Venkateswara University, Tirupati 517502, Andhra Pradesh, India \\ ${ }^{2}$ Human Genome Centre, School of Medical Sciences, Universiti Sains Malaysia, 16150 Kubang \\ Kerian, Malaysia \\ ${ }^{3}$ Department of Biochemistry, Sri Venkateswara Medical College, Tirupati 517502, Andhra Pradesh, India \\ ${ }^{4}$ Department of Zoology, Yogi Vemana University, Kadapa 516003, Andhra Pradesh, India
}

Correspondence should be addressed to Pasupuleti Visweswara Rao; visuthebiotech@gmail.com

Received 13 February 2013; Revised 11 March 2013; Accepted 16 March 2013

Academic Editor: William C. Cho

Copyright (C) 2013 Pasupuleti Visweswara Rao et al. This is an open access article distributed under the Creative Commons Attribution License, which permits unrestricted use, distribution, and reproduction in any medium, provided the original work is properly cited.

\begin{abstract}
The present study was conducted to evaluate the therapeutic efficacy of Rhinacanthus nasutus ( $R$. nasutus) on mitochondrial and cytosolic enzymes in streptozotocin-induced diabetic rats. The rats were divided into five groups with 6 rats in each group. The methanolic extract of $R$. nasutus was orally administered at a dose of $200 \mathrm{mg} / \mathrm{kg} / \mathrm{day}$, and glibenclamide was administered at a dose of $50 \mathrm{mg} / \mathrm{kg} / \mathrm{day}$. All animals were treated for 30 days and were sacrificed. The activities of both intra- and extramitochondrial enzymes including glucose-6-phosphate dehydrogenase (G6PDH), succinate dehydrogenase (SDH), glutamate dehydrogenase (GDH), and lactate dehydrogenase (LDH) were measured in the livers of the animals. The levels of G6PDH, SDH, and GDH were significantly reduced in the diabetic rats but were significantly increased after 30 days of $R$. nasutus treatment. The increased LDH level in diabetic rats exhibited a significant reduction after treatment with $R$. nasutus. These results indicate that the administration of $R$. nasutus altered the activities of oxidative enzymes in a positive manner, indicating that $R$. nasutus improves mitochondrial energy production. Our data suggest that $R$. nasutus should be further explored for its role in the treatment of diabetes mellitus.
\end{abstract}

\section{Introduction}

Type 1 diabetes mellitus (T1DM) is caused by the destruction of insulin-producing $\beta$ cells in the pancreas and is usually the result of an autoimmune disease. T1DM leads to uncontrolled blood glucose levels, which are associated with long-term damage, including retinopathy, neuropathy, nephropathy, and damage to the heart and blood vessels and with multiple organ failures [1]. To date, various types of herbs and other plant materials from all over the world have been used for the treatment of diabetes mellitus. Medicinal plants are a good source of compounds with hypoglycemic effects and are important for the development of new drugs and as adjuncts to existing therapies [2]. Some of the medicinal plants such as Panax ginseng and Piper longum possess significant antihyperglycemic and antihyperlipidemic actions which have been reported to have the potential to alleviate impaired oxidative stress in diabetic rats [3,4]. Generally, herbal products are gaining popularity due to their natural origins, the lower incidence of side effects, and their relatively lower costs relative to synthetic drugs [5], although their efficacies may still be inferior when compared to some current available treatments such as insulin and meformin.

Rhinacanthus nasutus (Linn) is a flowering plant that belongs to the Acanthaceae family and is well recognized for its remedial uses. This plant is commonly known as Nagamalli in Telugu, Doddapatika in Kannada, Kaligai and Anichi in Tamil, Yuthikaparni in Sanskrit, Jupani in Hindi, and Gajakarni in Marathi [6]. R. nasutus is also commonly known as Snake Jasmine due to the shape of its flowers. In addition, the root of this plant has been reported to be used in traditional medicine to counter the effects of snake venom [7]. Different parts of this plant have also been traditionally used for the treatment of various diseases 
such as diabetes, eczema, pulmonary tuberculosis, herpes, hypertension, hepatitis, and several types of skin diseases. In Thailand, $R$. nasutus has been traditionally used for the treatment of various cancers such as colon [8], cervical, and liver cancers [9].

Previously, we reported that $R$. nasutus possesses antimicrobial properties and can kill a variety of infecting organisms, in addition to exhibiting antidiabetic effects, hypolipidemic activity [10], and significant in vitro and in vivo antioxidant activities [11]. In this study, we hypothesized that $R$. nasutus may exert antidiabetic effects by ameliorating cytosolic and mitochondrial enzymes levels.

\section{Materials and Methods}

2.1. Collection of Plant Material. The fresh leaves of R. nasutus were collected from Tirumala Hills, Tirupati, and Chittoor district of Andhra Pradesh, in the period of July-October 2009. Seshachala and Tirumala Hills (Rayalaseema region, Andhra Pradesh, India), areas that are geographically located in the South Eastern Ghats, are recognized for their rich flora and fauna [12]. The plant specimen was verified to be of the correct species by Dr. Madhava Setty, a botanist from the Department of Botany, S. V. University, Tirupati.

2.2. Preparation of the Extract. Fresh leaves of $R$. nasutus $(500 \mathrm{~g})$ were shade-dried and milled into fine powder using a mechanical grinder (TTK Prestige, Chennai, India). The powdered plant material was macerated and shaken in methanol using a bath shaker (Thermo Scientific, Mumbai, India) for $48 \mathrm{~h}$. The extract was then filtered with filter paper (Whatman No. 1) and evaporated to dryness under vacuum and reduced pressure using a rotary evaporator at $40^{\circ} \mathrm{C}$. The concentrate was then placed on aluminum foil before freeze drying. The residual extract was dissolved in sterile water $(1 \mathrm{~mL})$ before use.

2.3. Chemicals. Streptozotocin (STZ) was purchased from Sigma (USA). All other chemicals and reagents used in this study were of analytical grade. Glibenclamide (Sugatrol, Hyderabad, India) was purchased from a local drug store.

2.4. Experimental Design. Adult male Wistar rats weighing between 150 and $180 \mathrm{~g}$ were obtained from Sri Venkateswara Enterprises, Bangalore. They were individually housed in clean, sterile polypropylene cages under standard conditions (12 h light/dark cycles) with free access to standard chow (Hindustan Lever Ltd., Bangalore, India) and water ad libitum. For one week prior to the start of the experiments, the animals were acclimatized in the laboratory. The animal experiments were designed and performed in accordance with the ethical norms approved by the local Ministry of Social Justices and Empowerment, Government of India, and the Institutional Animal Ethics Committee Guidelines (Resolution no. 05/(i)/a/CPCSEA/IAEC/SVU/MDNPVR/dt.13.09.2010).

2.5. Induction of Experimental Diabetes. The rats were divided into five groups of six animals each:
Group I. Normal rats (controls: animals receiving only buffer).

Group II. R. nasutus-treated normal rats $(200 \mathrm{mg} / \mathrm{kg} /$ day).

Group III. Diabetic rats (untreated).

Group IV. R. nasutus-treated diabetic rats $(200 \mathrm{mg} /$ $\mathrm{kg} /$ day).

Group V. Glibenclamide-treated diabetic rats $(50 \mathrm{mg} /$ $\mathrm{kg} /$ day).

The dose of $200 \mathrm{mg} / \mathrm{kg}$ was selected based on our previous study [13] where we found that $200 \mathrm{mg} / \mathrm{kg}$ dose gave similar effects to $250 \mathrm{mg} / \mathrm{kg}$ dose.

The toxicity of the extract has been tested. There were no toxic effects observed. There are some previous studies where it has been reported that the plant extract has no toxic effect when used in animals at higher doses also $500 \mathrm{mg} / \mathrm{kg}$ dose [8].

Diabetes was induced by a single intraperitoneal injection of a freshly prepared STZ solution (Sigma, no. 242-646-8) (50 mg/kg in citrate buffer $0.01 \mathrm{M}, \mathrm{pH} 4.5$ ) to overnight-fasted rats. Diabetes was confirmed by the presence of polydipsia and polyurea and by measuring the nonfasting plasma glucose levels $48 \mathrm{~h}$ after injection of STZ. Only animals that were confirmed to have blood glucose levels of greater than $250 \mathrm{mg} / \mathrm{dL}$ [1] were included. All of the animals were allowed free access to tap water and pellet show per the guidelines of the Institute Animal Ethics committee.

2.6. Phytochemical Analysis. Qualitative tests were conducted on the crude extract using various solvents such as hexane, ethyl acetate, methanol, and water for the different phytochemical constituents present in the plant extract based on the previous method described by Harborne [14].

2.7. Test for Glycosides (Keller-Kiliani Test). The test for glycosides was conducted based on the method published by Kokate et al. [15]. Briefly, the extracts were dissolved in glacial acetic acid, and two drops of ferric chloride solution (5\%, w/v in $90 \%$ alcohol) were added. The mixture was then transferred to a test tube containing $2 \mathrm{~mL}$ of concentrated sulfuric acid. The presence of a reddish brown ring between the two layers confirmed the presence of glycosides.

2.8. Test for Flavonoids. The test for flavonoids (lead acetate test) was conducted based on the method published by Peach and Tracey [16]. Briefly, several drops of lead acetate solution (10\%) were added to the alcoholic solution of the extract and a yellow precipitate was formed.

2.9. Test for Phenols. The presence of phenols (ferric chloride test) was confirmed using the method published by Trease and Evans [17]. Briefly, several drops of neutral ferric chloride solution (5\%, w/v in $90 \%$ alcohol) were added to the extract. A blackish green color indicated the presence of a phenolic group, indicating that the extract contained phenolic substances, which are antioxidants. 
2.10. Biochemical Measurements. All animals were sacrificed by cervical dislocation at the end of the experiment on day 30. The liver tissues were excised at $4^{\circ} \mathrm{C}$. The tissues were washed with ice-cold saline and were immediately immersed in liquid nitrogen and stored at $-80^{\circ} \mathrm{C}$ for further biochemical analysis. The activities of selected cytosolic enzymes were then assayed.

The activity of lactate dehydrogenase (LDH) was measured using the method adapted from Prameelamma and Swami [18] with slight modifications. The activity of glucose6-phosphate dehydrogenase (G6PDH) was measured using the method established by Lohr and Waller [19]. The levels of mitochondrial enzymes including succinate dehydrogenase (SDH) were assayed using a modified method published by Nachlas et al. [20]. The activity of glutamate dehydrogenase GDH) was determined by the method established by Lee and Lardy [21]. All enzymatic assays in this study were performed using crude liver homogenate.

2.11. Statistical Analysis. The results were expressed as the mean $\pm \operatorname{SD}(n=6)$. Statistical analysis was performed using one-way analysis of variance (ANOVA) followed by Tukey's test. $P<0.05$ was considered statistically significant.

\section{Results}

3.1. Phytochemical Analysis of Different Extracts of R. Nasutus. $R$. nasutus extracts produced using different solvents were screened for their phytochemical contents. Several compounds were confirmed to be present in the various types of extract (Table 1). Steroids were present in all of the extracts, whereas triterpenes and saponins were present only in the hexane and ethyl acetate extracts. Flavonoids, tannins, and carbohydrates were present in the aqueous extract. Glycosides were not detected in any of the extracts. Because the methanolic extract contained the highest concentrations of compounds, it was selected for further analysis.

3.2. The Effects of R. nasutus Extract on Cytosolic and Mitochondrial Enzymes. The oral administration of the R. nasutus extract to diabetic rats significantly reduced the LDH activity relative to that of diabetic control rats. This reduction was also observed for diabetic rats treated with glibenclamide, indicating that the activity of $R$. nasutus is similar to that of glibenclamide. However, no difference in LDH activity was observed in normal rats treated with $R$. nasutus (Figure 1), indicating that the effects of $R$. nasutus reverse the changes in $\mathrm{LDH}$ activity only in diabetic rats.

The activity of the mitochondrial marker enzyme SDH was significantly decreased in the diabetic rats. In this study, we demonstrated that the decrease in SDH activity among the diabetic rats was ameliorated by treatment with the $R$. nasutus extract. The increase in SDH activity in $R$. nasutus extracttreated diabetic rats was similar to the augmentation of the SDH activity by glibenclamide (Figure 2), indicating that $R$. nasutus has protective effects on SDH activity similar to those of glibenclamide.

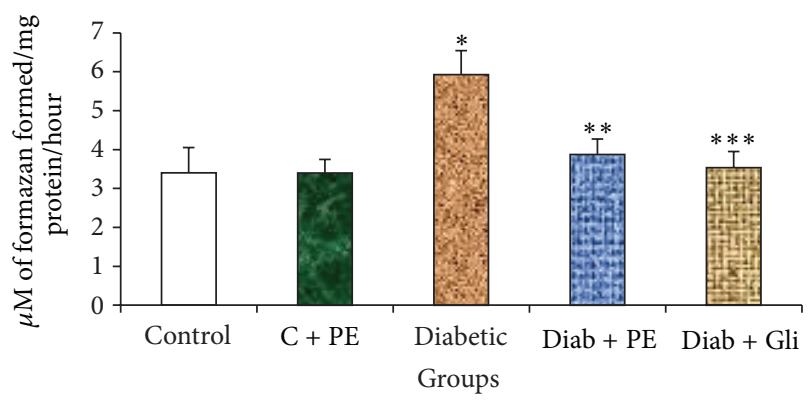

FIGURE 1: Changes in LDH activity in the liver tissue of experimental rats. Bars with the same superscripts do not differ significantly at $P<0.05 . \mathrm{C}=$ control, $\mathrm{PE}=$ plant extract, $\mathrm{Diab}=$ diabetic, $\mathrm{Gli}=$ glibenclamide.

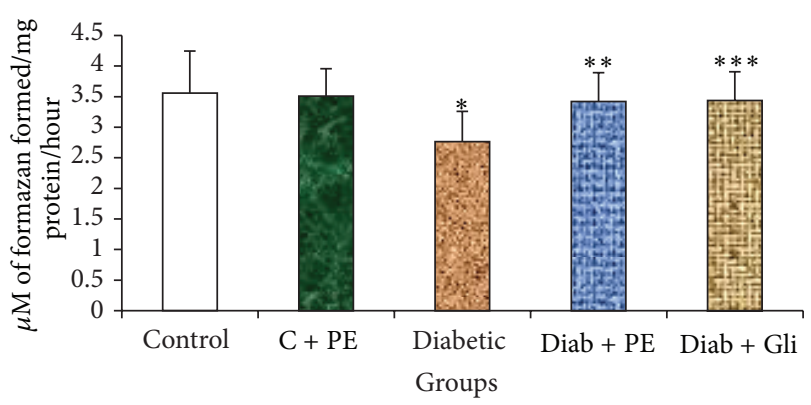

FIGURE 2: Changes in the SDH level in the liver tissue of experimental rats. Bars with the same superscripts do not differ significantly at $P<0.05 . \mathrm{C}=$ control, $\mathrm{PE}=$ plant extract, $\mathrm{Diab}=$ diabetic, $\mathrm{Gli}=$ glibenclamide.

STZ injection resulted in a significant decrease in GDH activity among animals in the diabetic group, a change that was not observed in normal control rats. Interestingly, we found a higher level of GDH activity in $R$. nasutus-treated diabetic rats compared with diabetic control rats. Treatment with the $R$. nasutus extract resulted in an improvement in the GDH activity that was equal to the improvement observed in the glibenclamide-treated diabetic rats (Figure 3), again indicating that the extract has protective effects on GDH activity similar to those of glibenclamide.

The G6PDH activity in diabetic rats was significantly decreased compared with that in the normal control rats. Conversely, diabetic rats treated with $R$. nasutus for 30 days exhibited a noticeable increase in G6PDH activity that was almost equal to that resulting from glibenclamide treatment (Figure 4), indicating that $R$. nasutus has positive effects on diabetes.

\section{Discussion}

Increased LDH activity in diabetic rats has been reported by various researchers [22-24]. In earlier reports, Singh et al. [25] reported that the $\mathrm{LDH}$ levels of diabetic rats were higher than those of the control rats and that the elevated LDH levels were associated with decreased insulin secretion. In diabetic animals, the extreme accumulation of 
TABLE 1: Phytochemical analysis of various extracts of R. nasutus.

\begin{tabular}{lcccc}
\hline Contents & Hexane & Ethyl acetate & Methanol & Water \\
\hline Steroids & + & + & + & + \\
Triterpenes & + & + & - & - \\
Saponins & + & + & - & - \\
Flavonoids & - & - & + & + \\
Phenolic compounds & - & - & + & - \\
Tannins & - & - & + & + \\
Carbohydrates & - & - & + & + \\
Glycosides & - & - & - & - \\
\hline
\end{tabular}

+ : present

$-:$ absent.

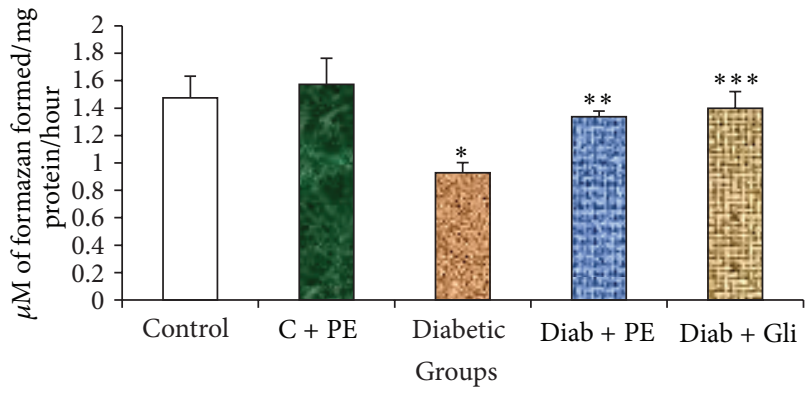

FIgure 3: Changes in the GDH level in the liver tissue of experimental rats. Bars with the same superscripts do not differ significantly at $P<0.05 . \mathrm{C}=$ control, $\mathrm{PE}=$ plant extract, $\mathrm{Diab}=$ diabetic, $\mathrm{Gli}=$ glibenclamide.

pyruvate may lead to higher LDH activity. In the presence of $\mathrm{LDH}$, excessive pyruvate is converted into lactate, leading to increased $\mathrm{LDH}$ activity, which could be attributed to the reduced insulin levels in diabetic individuals. Elevated LDH levels were observed in the STZ-induced diabetic rats and are associated with impaired glucose-stimulated insulin secretion [26]. Previous reports also suggest that other herbs such as Murraya koenigii and Ocimum sanctum can reduce LDH levels in diabetic rats [27]. However, the mechanism is still unclear.

The continuous administration of $R$. nasutus extract for 30 days reduced the LDH activities in diabetic rats in a manner parallel to that induced by glibenclamide. Glibenclamide is an oral antihyperglycemic drug that is used to treat diabetes due to its fast action, relatively low cost, and easy availability. Glibenclamide binds to the surface receptor present on the $\beta$ cells of the pancreas thereby reduces the conductance of the ATP-sensitive potassium channels. The reduction in potassium efflux causes membrane depolarization and the influx of calcium through calcium channels, which eventually causes insulin secretion [28]. The protective role of $R$. nasutus against these effects indicates that this plant is able to prevent the harmful effects of high LDH levels observed in diabetes.

$\mathrm{SDH}$ is one of the most important marker enzymes for mitochondria. Its activity is generally higher than that of other enzymes in both developing and adult animals. As reported by Satav and Katyare [29], the hepatic SDH activity was significantly decreased in STZ-induced diabetic

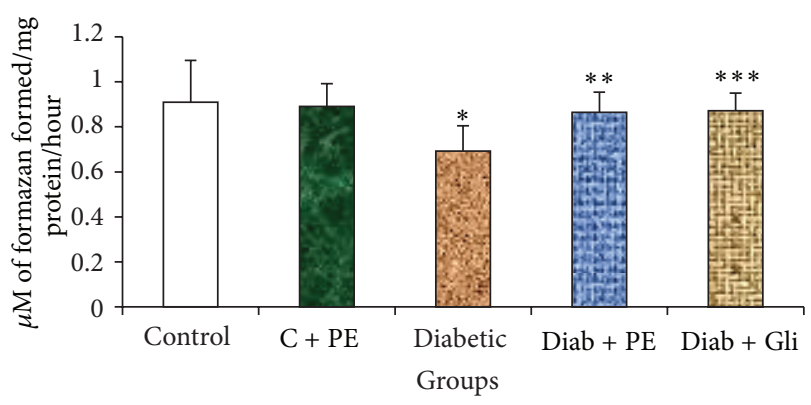

FIGURE 4: Changes in G6PDH in the liver tissue of experimental rats. Bars with the same superscripts do not differ significantly at $P<0.05 . \mathrm{C}=$ control, $\mathrm{PE}=$ plant extract, $\mathrm{Diab}=$ diabetic, $\mathrm{Gli}=$ glibenclamide.

rats. Diminished SDH activity in diabetic rats affects the succinate-fumarate conversion, contributing to depressed oxidative metabolism in mitochondria. It has been suggested that the diabetogenicity of STZ is due to the inhibition of the activities of citric acid cycle enzymes, such as SDH. In the present study, the SDH activity was ameliorated by $R$. nasutus treatment in diabetic rats. The presence of antioxidants, such as phenolic compounds, may have also contributed to this effect, as various antioxidants were confirmed to be present in this plant extract in our study. Further studies to investigate this association and to determine the exact composition of this extract will be useful. It has been reported that the increased SDH activity in diabetic rats treated with plant extracts is indicative of better energy utilization due to the production of intermediates in the tricarboxylic acid cycle [25]. Thus, our findings suggest that there is increased mitochondrial oxidative potential and energy synthesis when diabetic rats are treated with the methanolic extract of $R$. nasutus.

The regulation of ammonia levels in hepatic tissue is impaired in diabetic animals and humans [30]. In this study, the activity of GDH was significantly decreased in the livers of diabetic rats. This decrease in GDH activity may have been due to the instability of energy metabolism, the impairment of glutamate transport, or the activation of lipid peroxidation in the liver. In contrast, diabetic rats treated with $R$. nasutus extract exhibited improvements in GDH activity. The increased levels may be due to the synchronization of energy metabolism and the elevation of glutamate levels in the cells. The ameliorated activities of mitochondrial enzymes and GDH by treatment with a plant extract again suggest that this plant extract has a protective role against diabetes complications because a similar improvement in GDH activity was observed with the continuous administration of a standard antidiabetic drug, glibenclamide, for 30 days. Therefore, $R$. nasutus should be investigated further as a potential antidiabetic herb.

The extramitochondrial enzyme G6PDH is highly specific for NADP as an electron acceptor. The present results showed a dramatic decrease in the levels of G6PDH in the liver tissue of STZ-induced diabetic rats. These results were similar to those of previous studies that also demonstrated 
lower G6PDH activity in diabetic tissues [31-33]. It has been reported that hyperglycemia decreases the activities of hexose monophosphate shunt enzymes in diabetic animals and decreases G6PDH activity in diabetic rats. The reduced activity of G6PDH affects the NADPH concentrations in cells, thus contributing to oxidative stress, which can lead to diabetic complications [34]. In the present study, the elevated G6PDH activity observed with the continuous administration of $R$. nasutus to diabetic rats may help reduce diabetes-associated complications. The recovery of G6PDH activity in the plantextract-treated diabetic rats may be due to the antioxidants present in the leaves [35]; these antioxidants include phenolic groups, the presence of which we confirmed through phytochemical analysis. Further studies to identify the exact composition of the extract will be useful in the future.

STZ results in the irreversible destruction of $\beta$ cells and has been widely used to induce type 1 diabetes in experimental animal models. The considerable destruction of $\beta$ cells after STZ injection is purported to be due to the inhibition of free radical scavenging enzymes, thus encouraging the production of various free radicals $[36,37]$. This destruction of $\beta$ cells accounts for the marked decrease in the amount of insulin produced by the $\beta$ cells of the pancreas, which in turn affects glucose metabolism. In the present study, the observed significant increase in the blood glucose level in diabetic rats could be due to the destruction of pancreatic $\beta$ cells by STZ, strengthening the hypothesis that STZ induces diabetes via the generation of free radicals. Because the liver performs most of the reactions involved in the synthesis and utilization of glucose, it is plausible that the elevation of the glucose level in STZ-treated rats can be attributed by the oxidative stress produced in the pancreas due to single-strand breaks in the DNA of the pancreatic islets [38].

Some of the active constituents of $R$. nasutus have previously been reported. In a study conducted by Sendl et al. [39], rhinacanthin C and D were found to have antiviral activity, with effects comparable to those of ganciclovir and acyclovir. In another study, the in vitro antiproliferative activity of rhinacanthin $\mathrm{C}$ was reported to be comparable with or slightly weaker than that of the anticancer agent 5fluorouracil [40]. The researchers also confirmed that the in vitro antiproliferative activity of the ethanolic extract of $R$. nasutus roots was due to rhinacanthin $C$, whereas the activity of the aqueous extract of the leaves of $R$. nasutus was due to compounds other than rhinacanthin $C$ that are still unknown. Both the aqueous and ethanolicextracts of $R$. nasutus showed in vivo antiproliferative activity after daily oral administration once for only 14 days. To our knowledge, no studies have investigated the possible constituents of $R$. nasutus that contribute to the changes in the cytosolic and mitochondrial enzymes levels and can help control diabetes.

\section{Conclusion}

The continuous administration of $R$. nasutus for 30 days resulted in significant improvements in cytosolic and mitochondrial enzymes levels and activities, and these effects may contribute to the antidiabetic effects of this plant.

\section{Conflicts of Interests}

The authors declare that they have no conflicts of interests concerning this paper.

\section{Acknowledgments}

The corresponding author expresses thanks to Dr. Kasetti Ramesh Babu and Dr. Abdul Nabi, Department of Biochemistry, S. V. University, for providing him with the necessary facilities to complete the work.

\section{References}

[1] R. K. Babu, K. Vinay, S. K. Sameena, S. V. Prasad, S. Swapna, and A. R. C. Appa Rao, "Antihyperglycemic and antioxidant effects of Talinum portulacifolium leaf extracts in streptozotocin diabetic rats: a dose-dependent study," Pharmacognosy Magazine, vol. 5, no. 19, pp. 1-10, 2009.

[2] B. Sharma, C. Balomajumder, and P. Roy, "Hypoglycemic and hypolipidemic effects of flavonoid rich extract from Eugenia jambolana seeds on streptozotocin induced diabetic rats," Food and Chemical Toxicology, vol. 46, no. 7, pp. 2376-2383, 2008.

[3] W. C. S. Cho, W. S. Chung, S. K. W. Lee, A. W. N. Leung, C. H. K. Cheng, and K. K. M. Yue, "Ginsenoside Re of Panax ginseng possesses significant antioxidant and antihyperlipidemic efficacies in streptozotocin-induced diabetic rats," European Journal of Pharmacology, vol. 550, no. 1-3, pp. 173-179, 2006.

[4] S. Abdul Nabi, R. B. Kasetti, S. Sirasanagandla et al., "Antidiabetic and antihyperlipidemic activity of Piper longum root aqueous extract in STZ induced diabetic rats," BMC Complementary and Alternative Medicine, vol. 13, article 37, 2013.

[5] L. Pari and S. Srinivasan, "Antihyperglycemic effect of diosmin on hepatic key enzymes of carbohydrate metabolism in streptozotocin-nicotinamide-induced diabetic rats," Biomedicine and Pharmacotherapy, vol. 64, no. 7, pp. 477-481, 2010.

[6] K. R. Kirtikar and B. D. Basu, Indian Medicinal Plants with Illustration, vol. 3, International Book Distributors, Dehra Dun, India, 2nd edition, 2005.

[7] M. B. James and T. Tewin, "Rhinacanthus nasutus protects cultured neuronal cells against hypoxia induced cell death," Molecules, vol. 16, no. 8, pp. 6322-6338, 2011.

[8] P. Kupradinun, P. Siripong, R. Chanpai, S. Piyaviriyagul, A. Rungsipipat, and S. Wangnaitham, "Effects of Rhinacanthus nasutus Kurz on colon carcinogenesis in mice," Asian Pacific Journal of Cancer Prevention, vol. 10, no. 1, pp. 103-106, 2009.

[9] W. Rojanapo, A. Tepsuwan, and P. Siripong, "Mutagenicity and antimutagenicity of Thai medicinal plants.", Basic life sciences, vol. 52, pp. 447-452, 1990.

[10] P. Visweswara Rao, K. Madhavi, and M. Dhananjaya Naidu, "Hypolipideic properties of Rhinacanthus nasutus in streptozotocin-induced diabetic rats," Journal of Pharmacology and Toxicology, vol. 6, pp. 589-595, 2011.

[11] P. Visweswara Rao, P. Sujana, T. Vijayakanth, and M. Dhananjaya Naidu, "Rhinacanthus nasutus - its protective role in oxidative stress and antioxidant status in streptozotocin-induced diabetic rats," Asian Pacific Journal of Tropical Disease, vol. 2, no. 4, pp. 327-330, 2012.

[12] R. B. Kasetti, M. D. Rajasekhar, V. K. Kondeti et al., "Antihyperglycemic and antihyperlipidemic activities of methanol:water 
(4:1) fraction isolated from aqueous extract of Syzygium alternifolium seeds in streptozotocin induced diabetic rats," Food and Chemical Toxicology, vol. 48, no. 4, pp. 1078-1084, 2010.

[13] P. V. Rao and M. D. Naidu, "Anti diabetic effect of Rhinacanthus nasutus leaf extract in streptozotocin induced diabetic rats," Libyan Agriculture Research Center Journal International, vol. 1, no. 5, pp. 310-312, 2010.

[14] J. B. Harborne, Phytochemical Methods a Guide to Modern Techniques of Plant Analysis, Springer, New Delhi, India, 3rd edition, 2005.

[15] C. K. Kokate, A. P. Purohit, and S. B. Gokhale, Pharmacognosy, Nirali Prakashan, Pune, India, 4th edition, 1996.

[16] K. Peach and M. V. Tracey, Modern Method of Plant Analysis, Narosa Publishing House, New Delhi, India, 1959.

[17] G. E. Trease and W. C. Evans, Pharmacognosy, Bailliere Tindall, London, UK, 11th edition, 1978.

[18] Y. Prameelamma and K. S. Swami, "Glutamate dehydrogenase activity in the normal and denervated gastrocnemius muscle of frog. Rana hexadactyla," Current Science, vol. 44, pp. 739-740, 1975.

[19] G. D. Lohr and H. D. Waller, "Glucose 6-phosphate dehydrogenase," in Methods in Enzymatic Analysis, H. U. Bergmayer, Ed., vol. 2, pp. 636-643, Academic Press, London, UK, 1974.

[20] M. M. Nachlas, S. I. Margulies, J. D. Goldberg, and A. M. Seligman, "The determination of lactic dehydrogenase with a tetrazolium salt," Analytical Biochemistry, vol. 1, pp. 317-326, 1960.

[21] Y. P. Lee and H. A. Lardy, "Influence of thyroid hormones on L$\alpha$-glycerophosphate dehydrogenases and other dehydrogenases in various organs of the rat," The Journal of Biological Chemistry, vol. 240, pp. 1427-1436, 1965.

[22] M. Farswan, P. M. Mazumder, and V. Percha, "Protective effect of Cassia glauca Linn. on the serum glucose and hepatic enzymes level in streptozotocin induced NIDDM in rats," Indian Journal of Pharmacology, vol. 41, no. 1, pp. 19-22, 2009.

[23] S. S. Patel and R. K. Goyal, "Prevention of diabetes-induced myocardial dysfunction in rats using the juice of the Emblica officinalis fruit," Experimental \& Clinical Cardiology, vol. 16, pp. 87-91, 2011.

[24] M. Prasenjit and C. S. Parames, "Impaired redox signaling and mitochondrial uncoupling contributes vascular inflammation and cardiac dysfunction in type 1 diabetes: protective role of arjunolic acid," Biochimie, vol. 94, pp. 786-797, 2012.

[25] S. N. Singh, P. Vats, S. Suri et al., "Effect of an antidiabetic extract of Catharanthus roseus on enzymic activities in streptozotocin induced diabetic rats," Journal of Ethnopharmacology, vol. 76, no. 3, pp. 269-277, 2001.

[26] E. K. Ainscow, C. Zhao, and G. A. Rutter, "Acute overexpression of lactate dehydrogenase-A perturbs $\beta$-cell mitochondrial metasbolism and insulin secretion," Diabetes, vol. 49, no. 7, pp. 1149-1155, 2000.

[27] R. T. Narendhirakannan, S. Subramanian, and M. Kandaswamy, "Biochemical evaluation of antidiabetogenic properties of some commonly used Indian plants on streptozotocin-induced diabetes in experimental rats," Clinical and Experimental Pharmacology and Physiology, vol. 33, no. 12, pp. 1150-1157, 2006.

[28] L. Luzi and G. Pozza, "Glibenclamide: an old drug with a novel mechanism of action," Acta Diabetol, vol. 34, pp. 239-244, 1997.

[29] J. G. Satav and S. S. Katyare, "Effect of streptozotocininduced diabetes on oxidative energy metabolism in rat liver mitochondria-a comparative study of early and late effects,"
Indian Journal of Clinical Biochemistry, vol. 19, no. 2, pp. 23-31, 2004.

[30] G. A. Dudley, R. S. Staron, and T. F. Murray, "Muscle fiber composition and blood ammonia levels after intense exercise in humans," Journal of Applied Physiology Respiratory Environmental and Exercise Physiology, vol. 54, no. 2, pp. 582-586, 1983.

[31] K. Rasineni, R. Bellamkonda, S. R. Singareddy, and S. Desireddy, "Antihyperglycemic activity of Catharanthus roseus leaf powder in streptozotocin-induced diabetic rats," Pharmacognosy Research, vol. 2, no. 3, pp. 195-201, 2010.

[32] P. S. Sellamuthu, B. P. Muniappan, S. M. Perumal, and M. Kandasamy, "Antihyperglycemic effect of mangiferin in streptozotocin induced diabetic rats," Journal of Health Science, vol. 55, no. 2, pp. 206-214, 2009.

[33] J. Aseervatham, S. Palanivelu, and S. Panchanadham, "Semecarpus anacardium (Bhallataka) alters the glucose metabolism and energy production in diabetic rats," Evidence-based Complementary and Alternative Medicine, vol. 2011, Article ID 142978, 9 pages, 2011.

[34] M. Díaz-Flores, M. A. Ibáñez-Hernández, R. E. Galván et al., "Glucose-6-phosphate dehydrogenase activity and $\mathrm{NADPH} / \mathrm{NADP}^{+}$ratio in liver and pancreas are dependent on the severity of hyperglycemia in rat," Life Sciences, vol. 78, no. 22, pp. 2601-2607, 2006.

[35] H. Jiang, Z. Xie, H. J. Koo, S. P. McLaughlin, B. N. Timmermann, and D. R. Gang, "Metabolic profiling and phylogenetic analysis of medicinal Zingiber species: tools for authentication of ginger (Zingiber officinale Rosc.)," Phytochemistry, vol. 67, no. 15, pp. 1673-1685, 2006.

[36] P. K. Shankar, V. Kumar, and N. Rao, "Evaluation of antidiabetic activity of ginkgo biloba in streptozotocin-induced diabetic rats," Iranian Journal of Pharmacology and Therapeutics, vol. 4, pp. 16-19, 2005.

[37] G. R. Gandhi, S. Ignacimuthu, and M. G. Paulraj, "Hypoglycemic and b-cells regenerative effects of Aegle marmelos (L.) Corr. Bark extract in streptozotocin-induced diabetic rats," Food and Chemical Toxicology, vol. 50, pp. 1667-1674, 2012.

[38] P. Newsholme, E. P. Haber, S. M. Hirabara et al., "Diabetes associated cell stress and dysfunction: role of mitochondrial and non-mitochondrial ROS production and activity," The Journal of Physiology, vol. 583, pp. 9-24, 2012.

[39] A. Sendl, J. L. Chen, S. D. Jolad et al., "Two new naphthoquinones with antiviral activity from Rhinacanthus nasutus," Journal of Natural Products, vol. 59, no. 8, pp. 808-811, 1996.

[40] A. Gotoh, T. Sakaeda, T. Kimura et al., "Antiproliferative activity of Rhinacanthus nasutus (L.) KURZ extracts and the active moiety, rhinacanthin C," Biological and Pharmaceutical Bulletin, vol. 27, no. 7, pp. 1070-1074, 2004. 


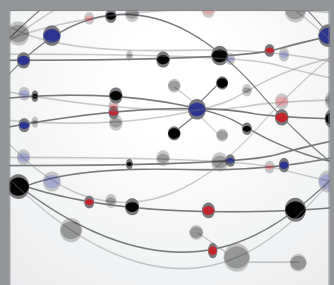

The Scientific World Journal
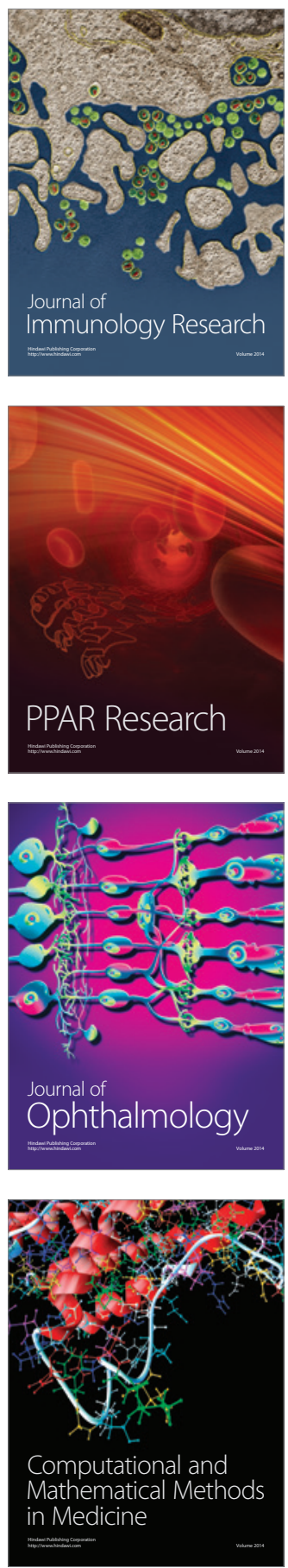

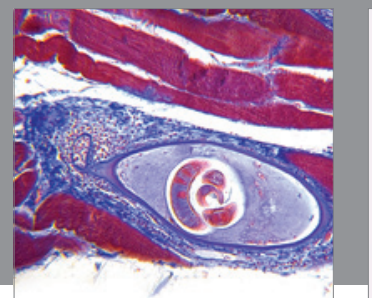

Gastroenterology

Research and Practice
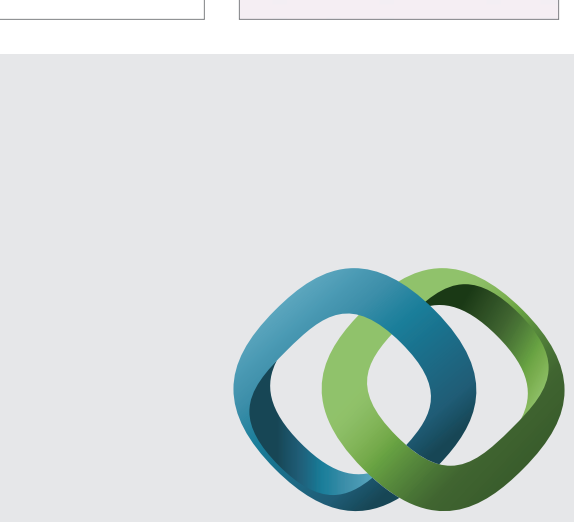

\section{Hindawi}

Submit your manuscripts at

http://www.hindawi.com
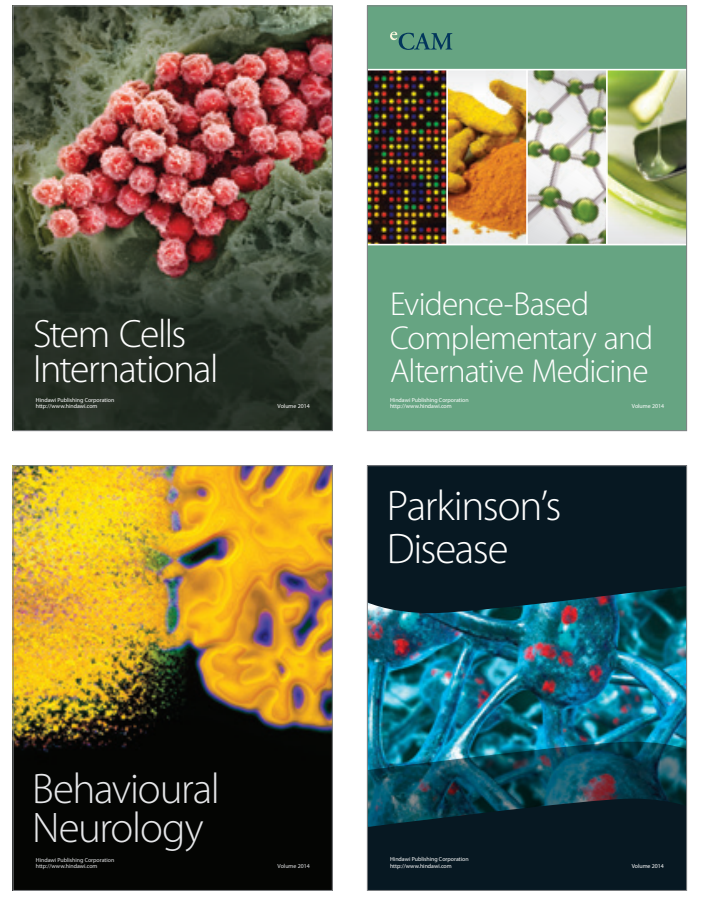
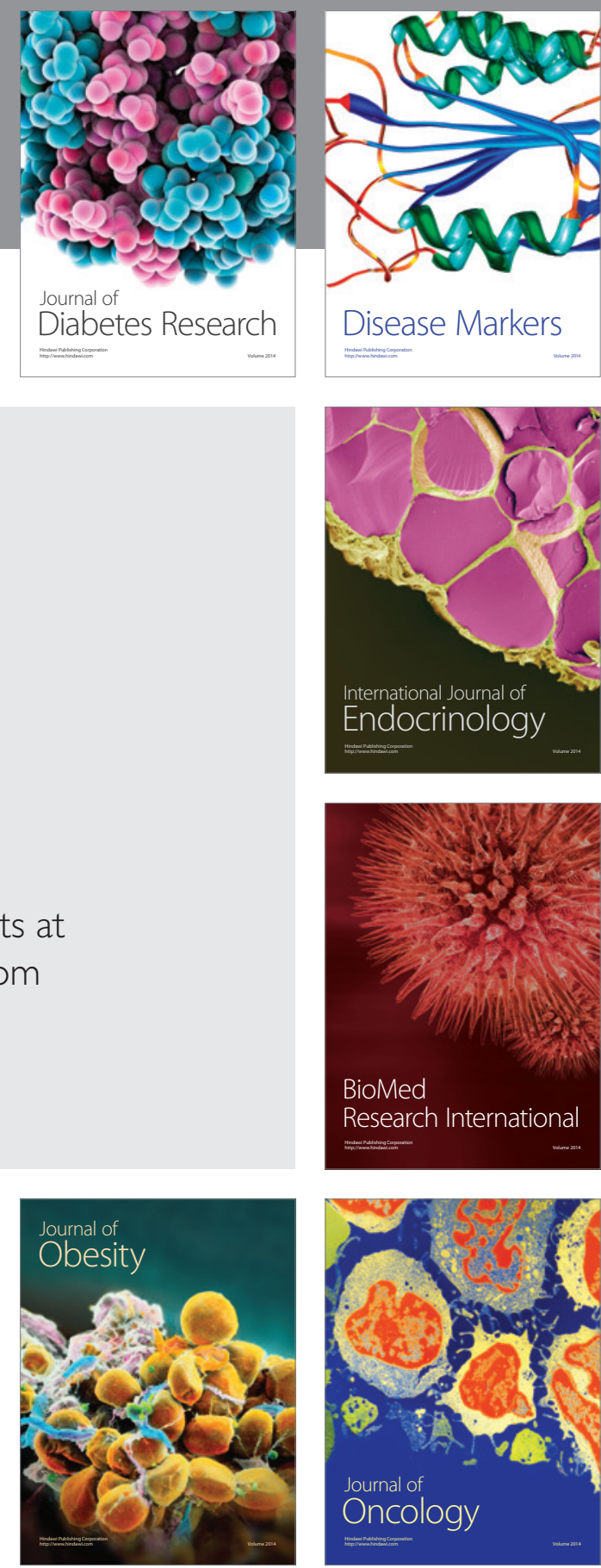

Disease Markers
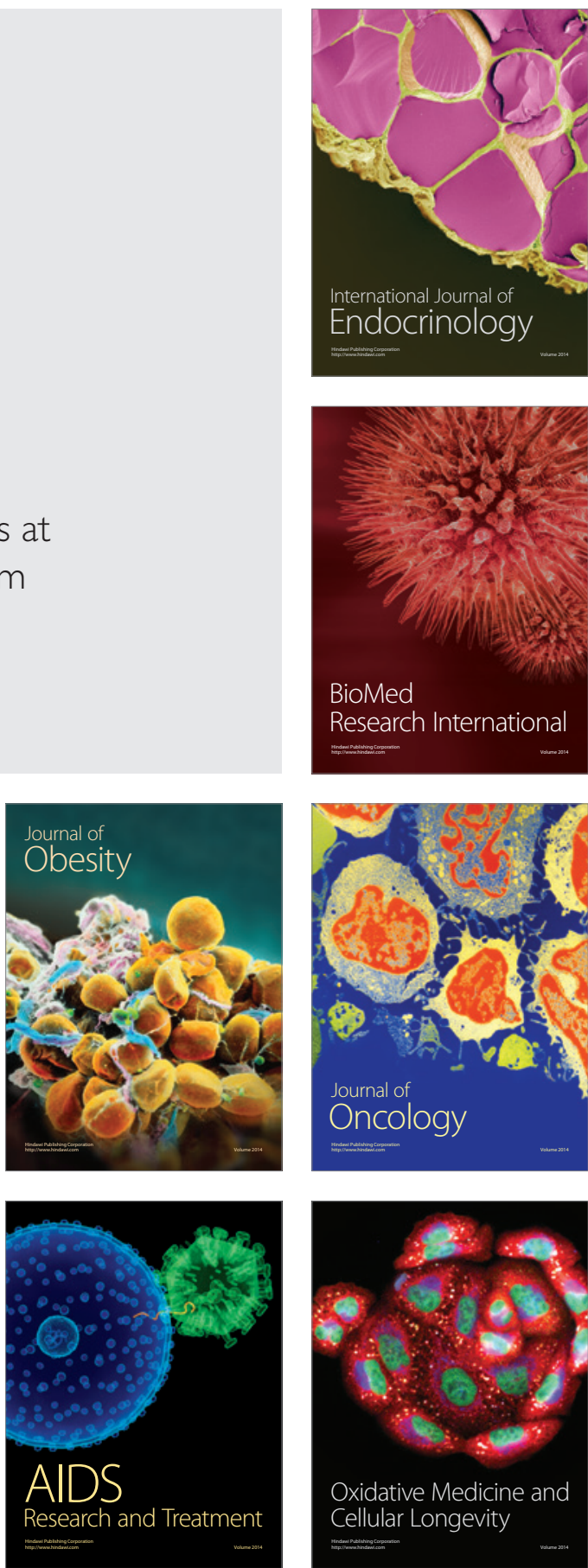